\title{
Mixed lineage leukaemia-4 regulates cell-cycle progression and cell viability and its depletion suppresses growth of xenografted
} tumour in vivo

\author{
KI Ansari', S Kasiri', BP Mishra' and SS Mandal',I \\ 'Department of Chemistry and Biochemistry, The University of Texas at Arlington, Arlington, TX 76019, USA
}

BACKGROUND: Mixed lineage leukaemia-4 (MLL4) is one of the MLL family of histone H3 lysine-4 (H3K4)-specific methyl transferases that have critical roles in gene expression and epigenetics in human. Though MLLs are well recognised as crucial players in histone methylation and gene regulation; little is known about the biochemical functions of MLL4 and its roles in cancer.

METHODS: Herein, we have investigated the roles of MLL4 in cell viability, cell-cycle progression and explored its potential roles in tumour growth using antisense-mediated knockdown experiments, flow-cytometry analysis, chromatin immunoprecipitation, immunofluorescence staining and animal models.

RESULTS: Our studies demonstrated that knockdown of MLL4 severely affects cell-cycle progression and induces apoptotic cell death in cultured tumour cells. Knockdown of MLL4 induced nuclear condensation, fragmentation, cytochrome-c release from mitochondria to cytosol and activated caspase-3/7 indicating apoptotic cell death. The MLL4 regulates expression of various critical cell-cycle regulatory genes such as cyclin D, cyclin E, p27, HOXA5 and HOXB7 via histone H3K4 trimethylation and recruitment of RNA polymerase II. Interestingly, application of MLL4 antisense suppressed tumour growth in vivo in colon cancer xenograft implanted in nude mouse. The MLL4 antisense specifically knocked down MLL4 in tumour tissue and also downregulated the expression of various growth and angiogenic factors resulting in tumour suppression.

CONCLUSION: Our results demonstrated that MLL4 is a crucial player in cell viability, cell-cycle progression and is critical for tumour growth in vivo.

British Journal of Cancer (2012) 1 07, 315-324. doi:10.1038/bjc.2012.263 www.bjcancer.com

Published online 19 June 2012

(c) 2012 Cancer Research UK

Keywords: mixed lineage leukaemia; MLL4; histone methylation; tumour suppression; tumour xenograft; MLL-antisense

Histone modifications have critical roles in gene expression, epigenetics and human diseases (Bannister and Kouzarides, 2005; Kouzarides, 2007). Among various histone modifications, functions of histone acetylation, methylation and phosphorylation have been extensively investigated and are recognised as crucial players in gene activation and silencing. In general, histone acetylation is associated with gene activation, while histone methylation is associated with both gene activation and silencing (Ajiro and Allis, 2002; Bannister and Kouzarides, 2005). Histone H3 lysine-4 (H3K4) methylation is linked with gene activation (Bhaumik et al, 2007). In human, there are several H3K4-specific histone methyl-transferases (HMTs) that include mixed lineage leukaemia (MLL) family of proteins (MLL1, MLL2, MLL3, MLL4 and MLL5), Set1A/Set1B and others (Ansari and Mandal, 2010). The MLLs are well known as master regulators of $H O X$ genes that are crucial players in cell differentiation and embryonic development (Hess, 2004; Guenther et al, 2005). The MLLs and their target genes are often associated with oncogenic transformation. For example, MLL1 is often rearranged in myeloid and lymphoid leukaemias (Hess, 2004; Marschalek, 2010). The MLL2 and MLL3 are

*Correspondence: Dr SS Mandal,; E-mail: smandal@uta.edu Received 28 February 2012; revised II May 2012; accepted 15 May 2012; published online 19 June 2012 frequently get mutated in medulloblastoma and large B-cell lymphoma (Parsons et al, 2011; Pasqualucci et al, 2011). High frequency of MLL2 mutation was also observed in Kabuki syndrome (Paulussen et al, 2010). The MLL1 and its fusion proteins are potential targets for developing novel cancer therapy (Marschalek, 2010; Hoeksema et al, 2011).

Because of the importance of MLLs in gene regulation and diseases, their biochemical functions and protein-protein interaction profiles have been investigated in great detail. These studies demonstrated that MLLs (MLL1-4) and Set1A/B exist as multiprotein complexes with several common subunits including Ash2, Wdr5, Rbbp5, Dpy30 and CGBP (Dou et al, 2006; Ansari and Mandal, 2010). The MLL1 is critical for cell-cycle progression and stress response (Mishra et al, 2009; Ansari and Mandal, 2010). Beyond their crucial roles in histone methylation, MLLs especially MLL2, MLL3 and MLL4 interact with nuclear hormone receptors (NRs) and coordinate in NR-dependent gene expression (Tan and Chow, 2001; Mo et al, 2006; Lee et al, 2009; Ansari et al, 2012). ASCOM complex that contains either MLL3 or MLL4 acts as co-activators in retinoic acid receptor (RXR)- and liver-X-receptormediated gene activation (Lee et al, 2008b). ASCOM containing MLL3 and MLL4 also acts as a p53 co-activator and regulate expression of p53-target genes in response to DNA damage (Lee et al, 2009). Thus, MLLs appear to be involved in diverse functions during gene expression, cell signalling and cancer. 
Though MLLs are well recognised as crucial players in histone methylation, gene regulation and cancer, most of the biochemical studies are focused towards understanding the functions of MLL1 and its fusion proteins. Biochemical functions of other MLLs such as MLL2, MLL3 and MLL4 in gene regulation, cell-cycle progression and tumorigenesis are mostly unexplored. Herein, we investigated the cellular functions of MLL4 and its roles in tumour growth in vitro and in vivo. Our studies demonstrated that MLL4 is critical for cell viability and cell-cycle progression and its knockdown suppressed the tumour growth in vivo in subcutaneously implanted colon cancer xenograft.

\section{MATERIALS AND METHODS}

\section{Cell culture, antisense design and transfection}

Human cervical cancer (HeLa), colorectal adenocarcinoma (SW480), non-malignant colon fibroblast (CCD-18Co), human adenocarcinoma mammary (MCF7), non-malignant mammary gland fibrocystic (MCF10), human bronchioalveolar carcinoma (H358), non-malignant lung fibroblast (HFL1) and human choriocarcinoma placenta (JAR) cells were obtained from ATCC (Manassas, VA, USA). Except H358 cells, all other cells were grown and maintained in Dulbecco's modified Eagle's medium (DMEM; Sigma, St Louis, MO, USA) supplemented with $10 \%$ fetal bovine serum, $1 \%$ L-glutamine and $0.1 \%$ penicillin/ streptomycin in a humidified $\mathrm{CO}_{2}$ incubator (Ansari et al, 2012). H358 cells were grown in RPMI-1640 media with all the supplements.

Two antisense oligonucleotide sequences for MLL4 (MLL4-A1: 5'-CCTTCTCTTCTCCCTCCTTGT-3'; MLL4-A2: 5'-CTTCCTTCTC TTCTCCCTCCT $-3^{\prime}$ ) corresponding to $+1123-1144$, and +1126 $-1147 \mathrm{nt}$ of MLL4 open reading frame (ORF) were designed and commercially synthesised (IDT-DNA). Each phosphodiester bond of the antisense oligonucleotides was replaced with phosphorothioate linkages to increase in-vivo stability. For the transfection, a cocktail of transfection reagents $(12 \mu \mathrm{l}$, iFECT; KD medicals Inc., Columbia, MD, USA) and antisense (3,5 and $7 \mu \mathrm{g}$ per $60 \mathrm{~mm}$ culture plate) were made in $300 \mu \mathrm{l}$ media (without supplements) and applied to the cells ( $60 \%$ confluency) in presence of $2 \mathrm{ml}$ of growth media (without supplements). Cells were then grown for $18 \mathrm{~h}$ and the growth media was replaced with normal media with all supplements, grown for additional times and harvested at $48 \mathrm{~h}$ post antisense treatment and subjected for RNA/protein extraction and chromatin immunoprecipitation (ChIP) analysis (Ansari et al, 2012).

\section{RNA/protein extraction, RT-PCR and western blots}

For the RNA extraction, control and antisense-treated cells $(48 \mathrm{~h}$ post transfection) were harvested by centrifugation ( $500 \mathrm{~g}$ ) for $10 \mathrm{~min}$, resuspended in diethyl pyrocarbonate (DEPC) treated buffer A (20 mM Tris- $\mathrm{HCl}, \mathrm{pH} 7.9 ; 1.5 \mathrm{~mm} \mathrm{MgCl}_{2} ; 10 \mathrm{~mm} \mathrm{KCl}$ and $0.5 \mathrm{~mm}$ DTT; $0.2 \mathrm{~mm}$ PMSF), incubated on ice for $10 \mathrm{~min}$, centrifuged at $3500 \mathrm{~g}$ for $5 \mathrm{~min}$. The supernatant was subjected to phenol-chloroform extraction followed by $\mathrm{LiCl}$ precipitation of mRNA (Ansari et al, 2012). The quality of the RNA was analysed based on integrity of the $28 \mathrm{~S}$ and $18 \mathrm{~S}$ ribosomal RNA (rRNA) by agarose gel electrophoresis. The RNA was quantified using UV-Vis spectroscopy $(\mathrm{A} 260 \mathrm{~nm})$ and the amounts of RNA in the antisensetreated samples were normalised against the untreated or scramble antisense-treated control RNA.

Reverse transcription reactions were performed in a total volume of $25 \mu \mathrm{l}$ containing $500 \mathrm{ng}$ of normalised total RNA, $2.4 \mu \mathrm{M}$ of oligo dT (Promega, Madison, WI, USA), 100 units of MMLV reverse transcriptase, $1 \times$ first strand buffer (Promega), $100 \mu \mathrm{M}$ each of dNTPs (Invitrogen, Grand Island, NY, USA), $1 \mathrm{mM}$ DTT and 20 units of RNaseOut (Invitrogen) and the CDNA was subjected to PCR amplification (28 cycles) with gene-specific primers (Table 1; Ansari et al, 2012).

For real-time PCR analysis, $5 \mu \mathrm{l}$ of cDNA was mixed with $5 \mu \mathrm{l}$ of SsoFast Eva Green super mix (Bio-Rad, Hercules, CA, USA) containing $200 \mu \mathrm{M}$ PCR primers for 40 cycles $\left(94{ }^{\circ} \mathrm{C}\right.$ for $15 \mathrm{~s}, 60^{\circ} \mathrm{C}$ for $30 \mathrm{~s}, 72{ }^{\circ} \mathrm{C}$ for 30 followed by a final extension for $5 \mathrm{~min}$ at $72{ }^{\circ} \mathrm{C}$ ) using CFX96 real-time PCR detection system (Bio-Rad). GAPDH was used as control. The experiments were repeated at least twice with three replicates each time $(n=6)$. The real-time PCR results were analysed using the CFX Manager software (Bio-Rad) and the expression of each gene relative to GAPDH was plotted.

For the protein extraction, control and antisense-treated $(48 \mathrm{~h})$ cells were suspended in whole cell protein extraction buffer $(20 \mathrm{~mm}$ Tris- $\mathrm{HCl} \mathrm{pH}$ 8.0, $350 \mathrm{mM} \mathrm{NaCl}, 5 \mathrm{mM}$ EDTA, 0.05\% NP-40, $0.2 \mathrm{~mm}$ PMSF and $1 \times$ protease inhibitors $\left.\left(1 \mathrm{mg} \mathrm{ml}^{-1}\right)\right)$ on ice for $20 \mathrm{~min}$ and centrifuged at $10000 \mathrm{~g}$ for $10 \mathrm{~min}$. The supernatant (protein extract) was subjected to western blotting using antibodies against MLL1 (Abgent, San Diego, CA, USA), MLL2 (Lifespan Biosciences, Seattle, WA, USA), MLL3 (Abgent), MLL4 (Sigma) and anti- $\beta$-actin (Sigma) and developed using alkaline phosphatase method.

\section{Cell viability assay, cytochrome- $c$ immunostaining and cytotoxicity (MTT assay) analysis}

For cell viability and microscopy assay, cells were transfected with MLL4 or scramble antisense for $48 \mathrm{~h}$, stained with trypan blue for $10 \mathrm{~min}$ and observed under a light microscope (Nikon Eclipse TE2000-U, Tokyo, Japan). For cytochrome-c immunostaining, MLL4 transfected or control cells were immunostained with anticytochrome-c antibody followed by FITC-conjugated secondary antibody, subjected to nuclear staining with DAPI and observed under fluorescence microscope (Ansari et al, 2009). For caspase assay, cells were transfected with MLL4 or scramble antisense for $48 \mathrm{~h}$, harvested, lysed, centrifuged and the supernatant was subjected to caspase-3/7 activity assay using SensoLyte TM Homogenous AMC Caspase-3/7 Assay Kit (AnaSpec Inc., Fremont, CA, USA) (Ansari et al, 2009). For TUNEL assay, MLL4 antisensetransfected cells were fixed in $1 \%$ formaldehyde, permeabilised in $0.2 \%$ Triton X-100, and subjected to dUTP-end labelling (ApoAlert DNA Fragmentation Assay Kit; Clontech, Mountain View, CA, USA), stained with DAPI and propidium iodide (PI) and visualised under fluorescence microscope (Ansari et al, 2009). For MTT assay, $\sim 10000$ cells were seeded into each well of a 96-well micro titer plate overnight, transfected with MLL4/scramble antisenses (for $48 \mathrm{~h}$ ) and analysed by using MTT assay (Ansari et al, 2009). The percent viable cells (calculated based on absorbance of the control untreated sample) were plotted. Each experiment (with five replicates) was repeated at least twice.

\section{Flow-cytometry analysis}

SW480 cells were transfected with MLL4 and scramble antisense oligonucleotides separately using iFECT transfection reagents $(48 \mathrm{~h})$, harvested, fixed in $70 \%$ ethanol for $2 \mathrm{~h}$, washed twice with PBS and stained with PI (final concentration, $0.5 \mu \mathrm{g} \mathrm{ml}^{-1}$ ). The cells were analysed by flow cytometry, using a Fusing Beckman Coulter Cytomics FC500 flow cytometry analyser (Beckman Coulter Inc., Brea, CA, USA) (Mishra et al, 2009).

\section{ChIP assay}

SW480 cells were transfected with MLL4 or scramble antisenses for $48 \mathrm{~h}$, fixed with $4 \%$ formaldehyde, washed, lysed, and sonicated until chromatin was sheared to an average DNA fragment length of $0.2-0.5 \mathrm{~kb}$ and subjected to ChIP assay using various antibodies as described previously (Mishra et al, 2009).

\section{Colon cancer xenograft and MLL4 antisense-mediated tumour suppression}

For animal studies, the mice were hosted in the UT Arlington animal care facility under the supervision of trained personal and the experiments were carried out using Institutional animal care 
Table I Nucleotide sequence of antisense and primers used in PCR analysis

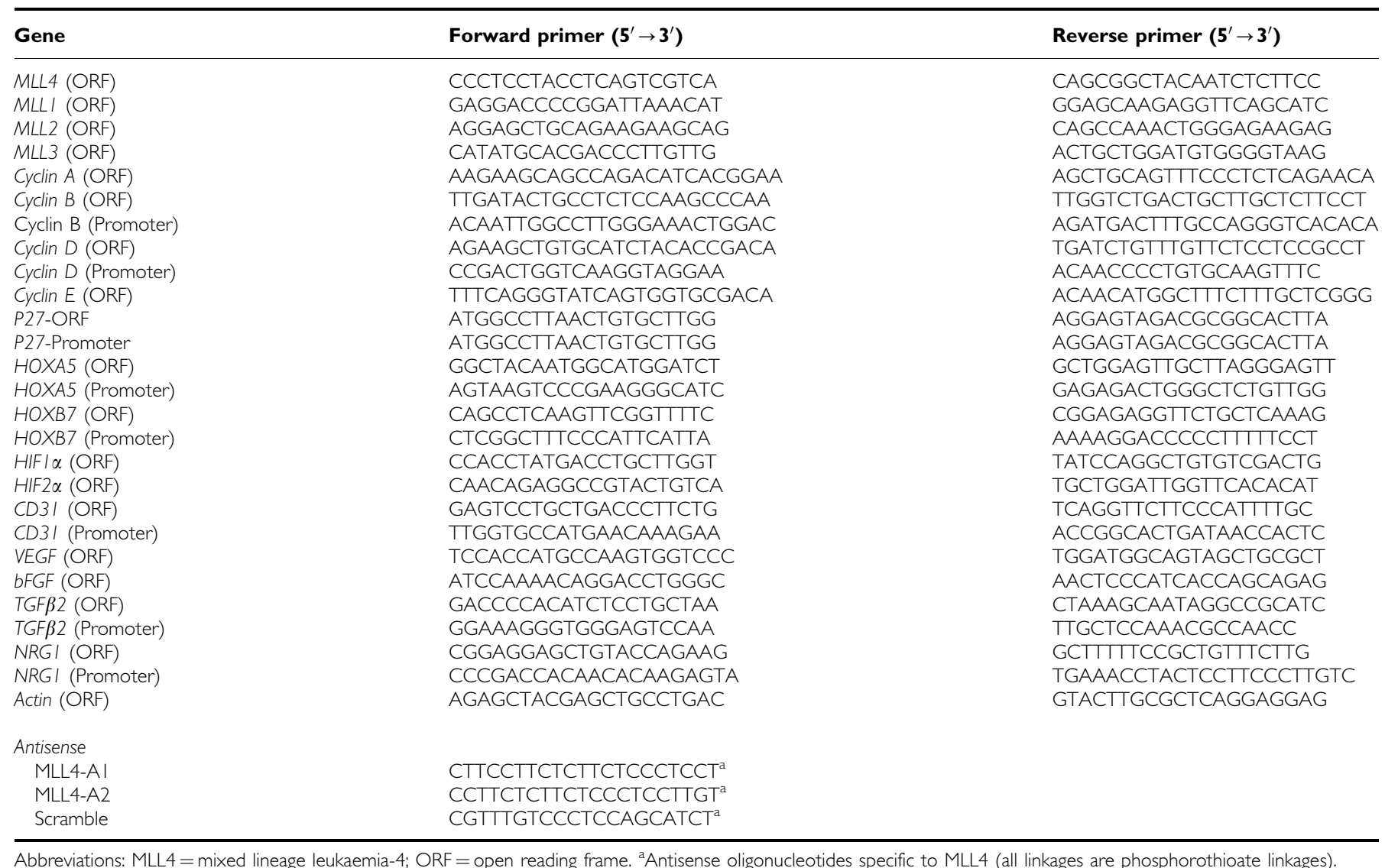

and use committee (IACUC)-approved protocol. For analysing toxicity, 6-week-old Athymic nude (nu/nu) mice (Harlan, Indianapolis, IN, USA) were injected intraperitoneally with three doses (100, 300 and $500 \mu \mathrm{g}$ per $20 \mathrm{~g}$ body weight) of MLL4 or scramble antisense (three replicates each). Health conditions (body weight, growth and behaviour) of each mouse were monitored on a daily basis for a month. For the xenograft experiments, $2 \times 10^{6}$ colon cancer cells (in $100 \mu \mathrm{l}$ PBS) were subcutaneously injected near the right back limb (Wang et al, 2002; Singhal et al, 2007). Mice were examined daily for signs of tumour growth and behaviour. Once the tumour size reached $\sim 32 \mathrm{~mm}^{2}$, MLL4 antisense $(300 \mu \mathrm{g}$ per $20 \mathrm{~g}$ body weight in PBS) was administered intraperitoneally at 4 days interval for 4 weeks. Experiments (with three replicate mice) were repeated at least twice. Control mice were injected with equal volume of the diluents (PBS) or scramble antisense alone. Bidirectional measurement of tumour sizes was done at every 2 days intervals and cross-sectional areas (tumour size) were plotted.

\section{RNA/protein extraction and immunohistological analysis of tumour xenograft tissue}

For RNA and protein extraction, tumour xenografts were excised from euthanised mice, flash frozen in liquid nitrogen, homogenised, and subjected to RNA (ZyGEM kit, Hamilton, New Zealand) and protein extraction. The RNA was reverse transcribed to cDNA and subjected to qPCR. The protein extract was subjected to western blotting. For ChIP and immunohistochemical staining, mice were sequentially perfused with cold PBS ( $\mathrm{pH} 7.4$ ), followed by $4 \%$ paraformaldehyde (in PBS), and then the xenografted tumours were removed, cryoprotected in PBS containing 30\% sucrose and sectioned.

For immunohistochemical staining (fluorescent), the xenografted tumour sections were blocked with goat serum, incubated (2h) with antibodies specific to MLL4 washed and incubated with FITC or rhodamine-conjugated secondary antibodies (Jackson Immuno Research Laboratories, West Grove, PA, USA). Nuclear counterstaining was performed with DAPI. Immunostained tissues were mounted and observed under a fluorescence microscope.

\section{RESULTS AND DISCUSSION}

MLL4 is critical for cell viability and its knockdown induces apoptosis in cultured cells

To examine the importance of MLL4 in cell viability we knocked it down in different types of cultured human cells using MLL4specific phosphorothioate antisense oligonucleotide. Initially, we designed and screened two MLL4-antisense oligonucleotides (MLL4-A1 and MLL4-A2, see Table 1) that hybridise at the 1123-1144 and 1126-1147 nucleotide positions of the MLL4 ORF which is 8148 nucleotides, encoding a 2715 aa long protein. Notably, there are four MLL homologues (MLL1, MLL2, MLL3 and MLL4) in human that have H3K4-specific HMT activities, exist as similar multi-protein complexes inside cells and have crucial roles in gene activation (Dou et al, 2006). Sequence alignment showed that MLL4 antisenses do not posses any significant homology to other MLL (MLL1-3) ORFs. Nevertheless, we examined both MLL4 antisenses (MLL4-A1 and MLL4-A2) for their efficacy and specificity towards knocking down MLL4 in cultured human cell lines. The data showing the knockdown efficacy and specificity of MLL4-A2 (the more active antisense, termed as MLL4 antisense) are shown in Figure 1 and this antisense was used for all experiments in our study. 

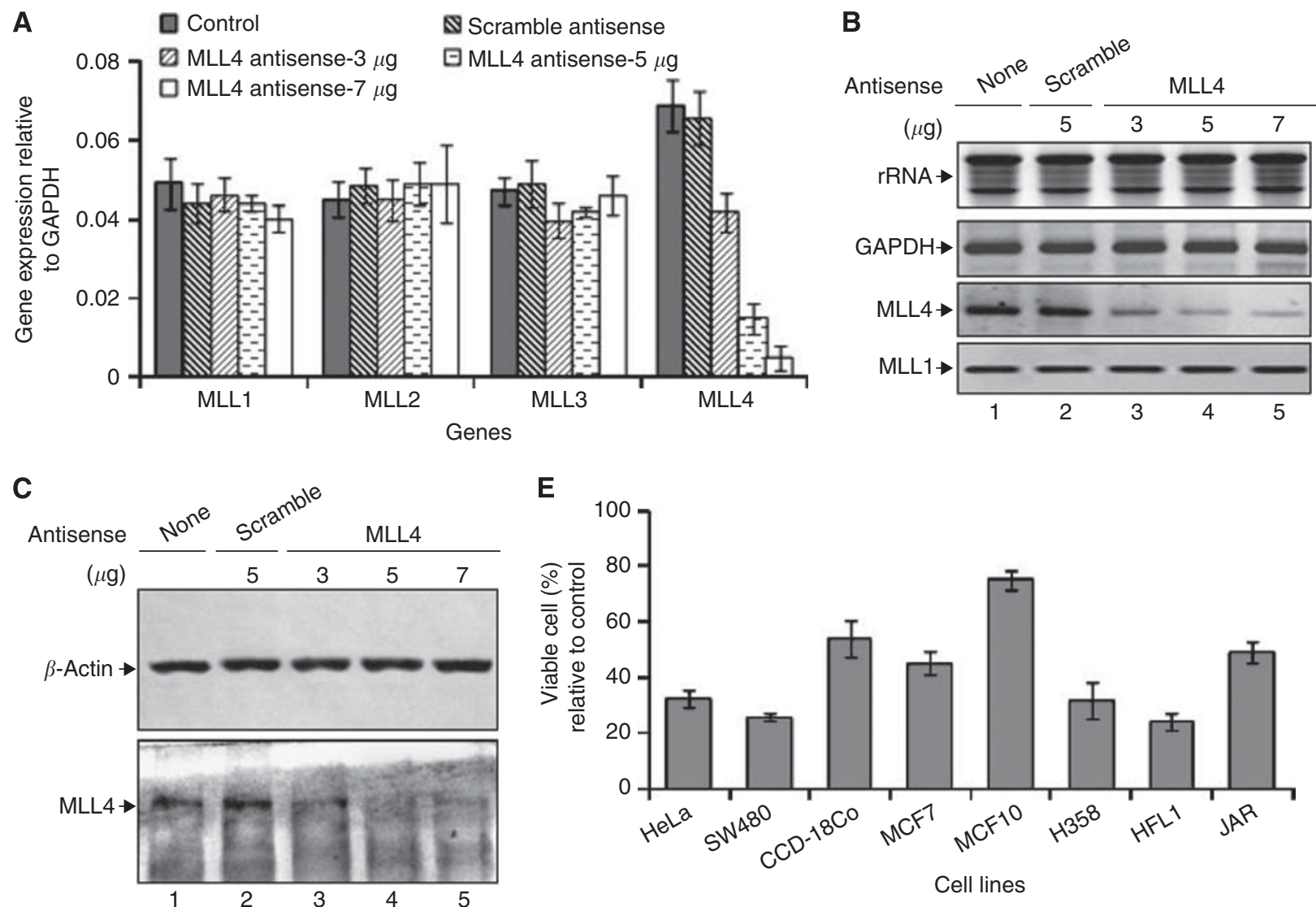

D
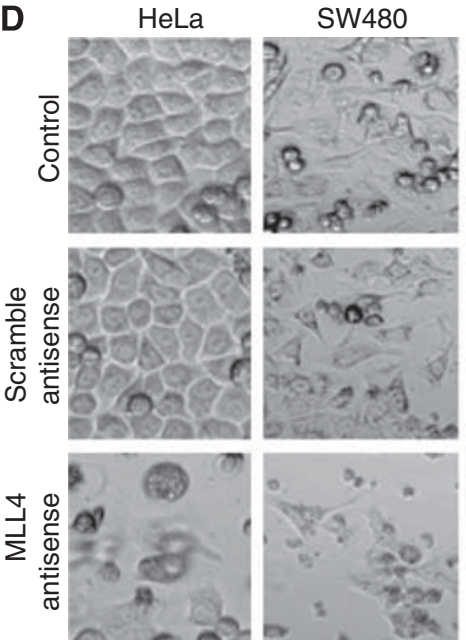
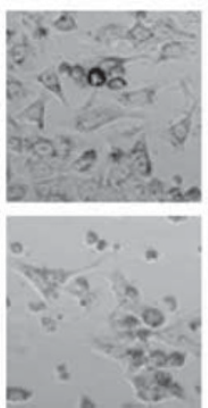

CCD-18Co
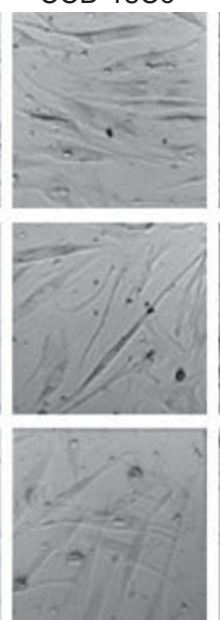
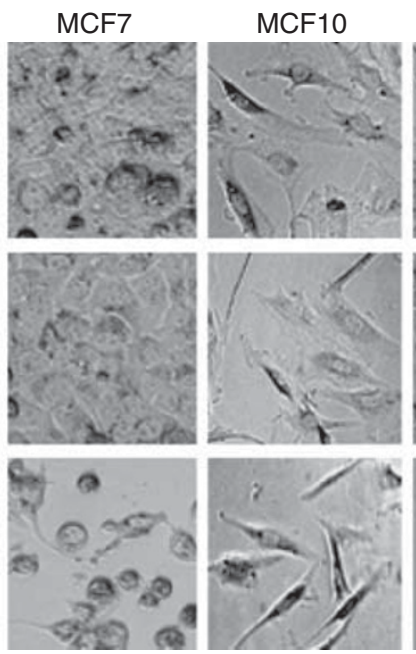
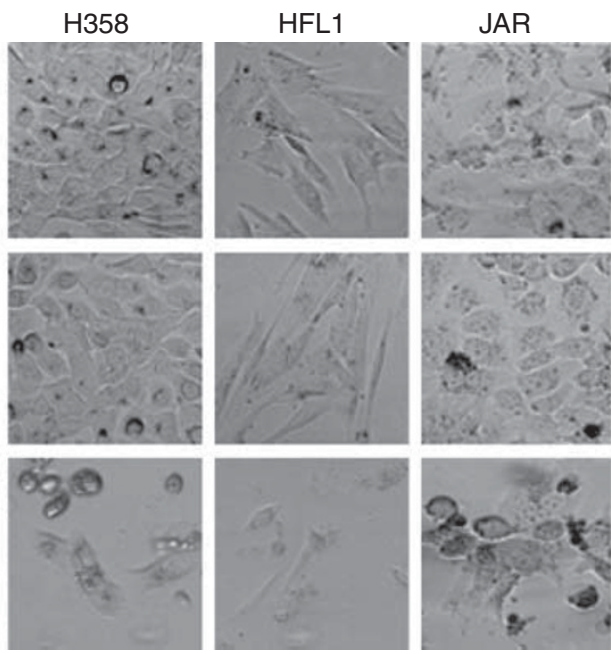

Figure I MLL4 knockdown and its effect on cell viability. (A) Effect of MLL4 knockdown on the expression of MLLI-4: colon cancer (SW480) cells were transfected with varying concentrations of MLL4 antisense for $48 \mathrm{~h}$. RNA was reverse transcribed and subjected to real-time PCR analysis using primers specific to MLLI, MLL2, MLL3, MLL4 and GAPDH. The expression of different MLLs relative to GAPDH was plotted. GAPDH expression and rRNA levels were used as loading control. Each experiment was performed in three replicates for at least two times. Bars indicate standard errors. (B) RNA from the control and MLL4 antisense-treated cells were subjected to RT-PCR using primer specific to MLL4, MLLI (specificity control) and GAPDH (loading control) and then analysed by agarose gel electrophoresis. Lane I: control cells; lane 2: cells transfected with scramble antisense; lanes 3-5: cell transfected with 3-7 $\mu \mathrm{g}$ of MLL4 antisense. (C) Western blotting: proteins from the control and MLL4 antisense-treated cells were subjected to western blotting using antiMLL4 and anti- $\beta$-actin antibodies (loading control). (D) Microscopic images showing different cancer and non-cancer cells transfected with MLL4 or scramble antisense for $48 \mathrm{~h}$. Control cells were treated with PBS (buffer) alone. (E) MTT assay: cells were transfected with $7 \mu \mathrm{g}$ MLL4 or scramble antisense for $48 \mathrm{~h}$ and then subjected to MTT assay. The relative (\%) cell viability (MLL4 antisense vs scramble antisense) was plotted for different cell lines. Bars indicate standard errors.

To examine the efficacy of the antisense, we transfected colon cancer cells (SW480) with varying doses (3-7 $\mu \mathrm{g}$ ) of MLL4 and scramble antisense (that has no homology to MLL4) separately (Table 1) for $48 \mathrm{~h}$. RNA and proteins from the antisense-treated and control cells were analysed by real-time PCR (qPCR) and western blotting. Real-time PCR analysis demonstrated that transfection with MLL4-antisense oligonucleotide efficiently and specifically knocked down MLL4, but not MLL1, MLL2 or MLL3 
(Figure 1A; Supplementary Figure S1). The scramble antisense had no significant effect on MLL4 expression level (Figure 1A-C). RT-PCR products from MLL4-knocked down and control samples were analysed in agarose gel and these results also demonstrated that MLL4 was specifically and effectively knocked down by MLL4-antisense transfection (compare lanes 3-5 with lane 1, Figure 1B). The rRNA, GAPDH and MLL1 were used as controls (Figure 1B). Western blot analysis also demonstrated that MLL4 was knocked down at the protein level upon transfection with MLL4 antisense while other MLLs and $\beta$-actin level were remained mostly unaffected (Figure 1C; Supplementary Figure S2). These results demonstrated that MLL4 antisense specifically knocked down MLL4.

To examine the impact of MLL4 kncokdown on cell viability, we transfected different types of cultured human cells with MLL4 antisense and examined their morphology under microscope (Figure 1D) and quantified the cell viability using MTT assay (Figure 1E). These analyses showed that MLL4 knockdown significantly impaired the growth and morphology of almost all cell lines examined (Figure 1D and E; Supplementary Figure S3). Cells were arrested, rounded up and fragmented indicating cell death (Figure 1D). The MTT assay demonstrated that the viability of most cells was decreased upon MLL4 knockdown (Figure 1E). Colon and breast cancer cells were more sensitive to MLL4 knockdown in comparison with the corresponding normal cells. These studies demonstrated that MLL4 is a critical player for cell viability and its suppression induced cell death. As MLL4 knockdown induced preferential death in colon cancer over colon normal cells we performed the remaining biochemical and in-vivo experiments with colon cancer cells (SW480).

\section{MLL4 knockdown affects cell-cycle progression and induced apoptosis in colon cancer cells}

To examine the impact of MLL4 knockdown on cell-cycle progression, we transfected SW480 cells with MLL4 antisense for $48 \mathrm{~h}$ and subjected to flow-cytometry analysis. As seen in Figure 2A, in comparison with the control, the scramble-antisense treatment induced some cell death ( $16 \%$ apoptosis) and also effected cell populations at G0/G1 phase (decreased in comparison with control). This change is likely due to the toxic effect of the transfection reagent used. Interestingly, however, upon application
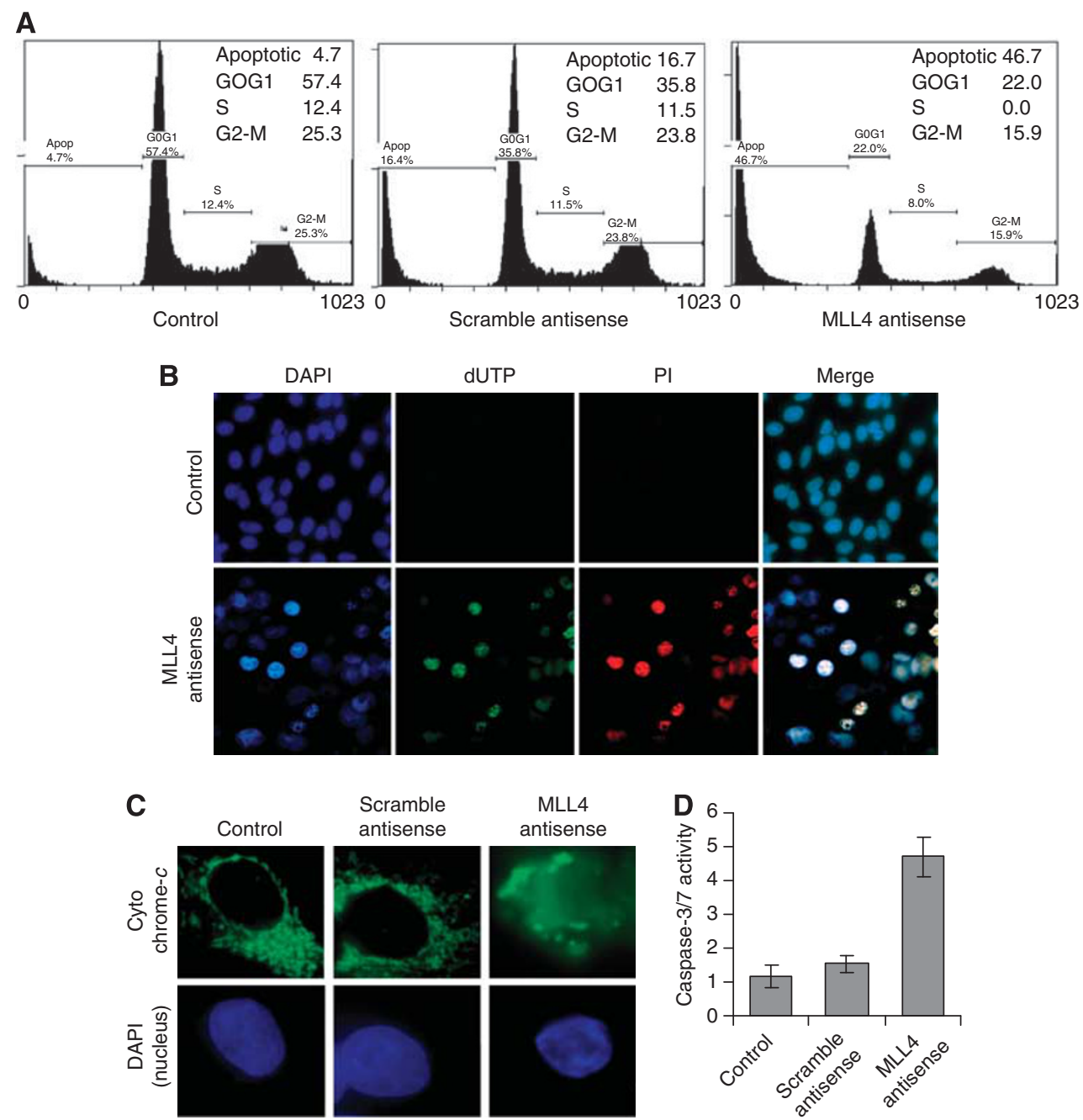

Figure 2 MLL4 knockdown induced apoptosis in colon cancer cell. SW480 cells were transfected with MLL4 antisense or scramble for $48 \mathrm{~h}$ then subjected to different analysis. (A) FACS analysis: MLL4 and scramble antisense-transfected cell was fixed, stained with propidium iodide (PI) and analysed by using Beckman Coulter Cytomics FC500 flow cytometry analyser. Percent cell populations at different stages of cell cycle are listed within the panels. (B) TUNEL assay. MLL4 antisense-treated and control cells were subjected to terminal nicked end-labelling using fluorescent dUTP, stained with DAPI (nuclear staining, blue fluorescence) and PI (PI that stains nucleus of dead cells, red colour) and analysed under fluorescence microscope. dUTP-stained green speckles represent apoptotic cells with fragmented nuclei. (C) Immunostaining of cytochrome-c: MLL4 antisense-treated and control cells were immunostained with cytochrome-c antibody followed by FITC-labelled secondary antibody, stained with DAPI and visualised under fluorescence microscope. (D) Caspase analysis: MLL4 antisense (or scramble antisense) cell lysates were analysed for caspase activity using Caspase-3/7 assay kit. Bars indicated standard error. 
of the MLL4 antisense, the cell populations at G0/G1, S as well as G2/M phases were decreased dramatically in comparison with the control or scramble antisense-treated cells and most cells (47\%) went into apoptosis (Figure 2A, bottom panel). These results demonstrated that MLL4 is a key regulator of cell-cycle progression and its knockdown severely impaired cell-cycle progression and induced apoptosis in colon cancer cells.

Notably, induction of apoptosis by external or internal stimuli leads to perturbed mitochondrial membrane potential, resulting in release of cytochrome $c$ to cytosol that ultimately leads to caspase activation, nuclear fragmentation and apoptosis (Orrenius et al, 2007; Ansari et al, 2009). To further understand the nature of cell death upon MLL4 knockdwn, we treated SW480 cells with MLL4 antisense for $48 \mathrm{~h}$ and subjected to DAPI (a DNA binding dye that stains nucleus) staining and TUNEL assay (Ansari et al, 2009). DAPI staining showed that MLL4 knockdown induced nuclear condensation (intense DAPI staining) (Figure 2B). TUNEL assay demonstrated that nuclear DNA was fragmented upon MLL4antisense treatment (green coloured nuclei, dUTP panels in Figure 2B). Notably, PI (PI stains nucleus of dead cells) staining demonstrated that all the cells that were stained green with dUTP were also stained with PI indicating apoptotic cell death (Figure 2B)

To examine mitochondrial membrane potential and integrity, we have immunostained MLL4 antisense-treated cells with cytochrome- $c$. As expected, cytochrome-c is located inside the mitochondria (speckles outside the nucleus) in both control or scramble antisense-treated cells (Figure 2C, top panels). However upon MLL4 knockdown, cytochrome $c$ was released from mitochondria to cytosol (Figure 2C). In addition, caspase analysis demonstrated about five-fold higher caspase-3/7 activity in the cells treated with MLL4 antisense in comparison with untreated or scramble antisense-treated controls (Figure 2D). The DNA fragmentation, nuclear condensation, cytochrome- $c$ release and caspase-3/7 activation demonstrated that MLL4 knockdown induced apoptosis in SW480 cells.

\section{MLL4 is a key regulator of cell-cycle regulatory genes}

As MLL4 knockdown affected the cell-cycle progression and induced apoptosis in colon cancer cells, we examined the effect of MLL4 knockdown on expression of cell-cycle regulatory genes
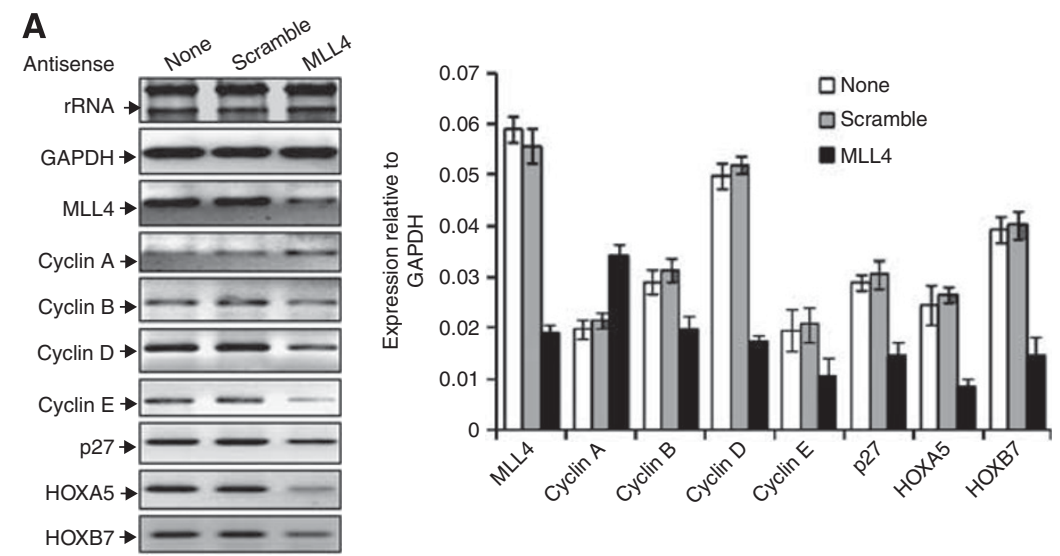

B
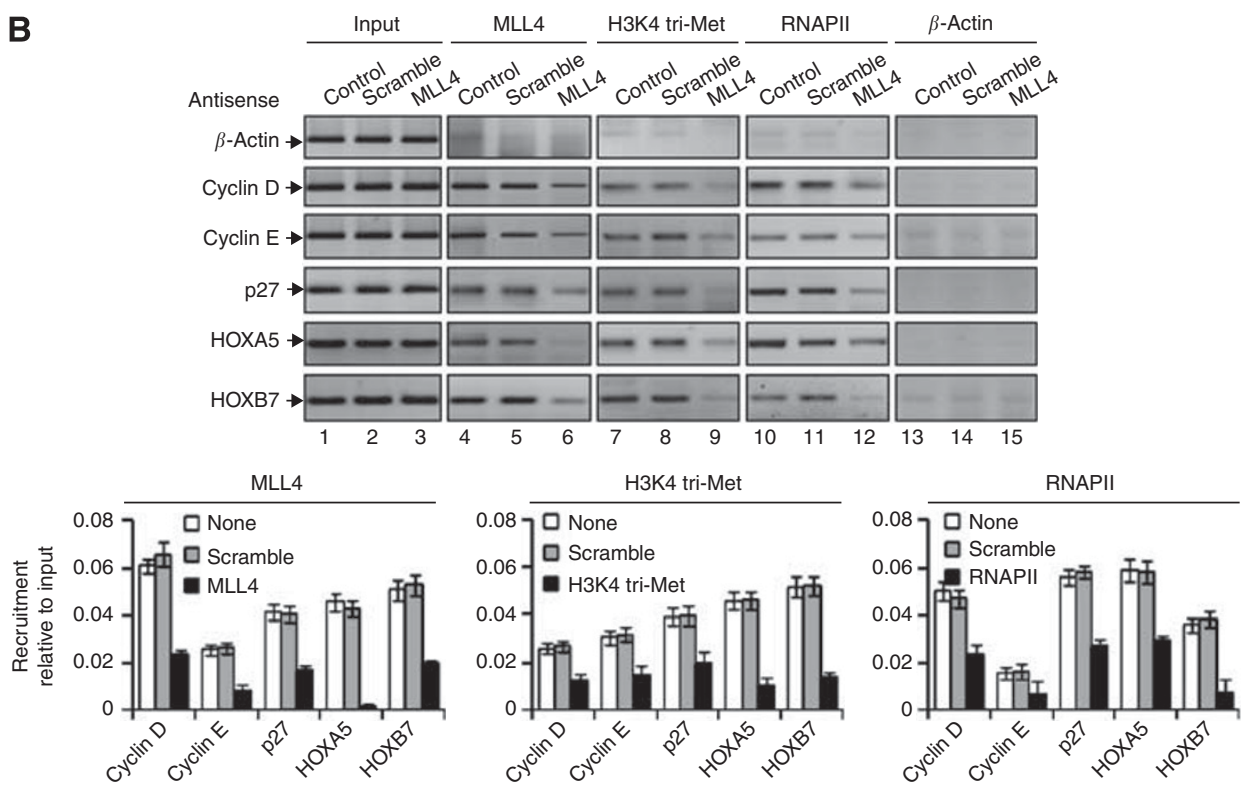

Figure 3 MLL4 regulates cell-cycle regulatory cyclins, p-protein and HOX genes. SW480 cells were transfected with MLL4 antisense for $48 \mathrm{~h}$ and the subjected to RNA extraction or ChIP assay. (A) RNA from MLL4-knocked down or control cells analysed by RT-PCR by using primers specific to selected cell-cycle regulatory genes (cyclin A-E, p27, HOXA5 and HOXB7) and GAPDH. GAPDH expression and rRNA levels were used as loading control. (B) ChIP assay: MLL4 and scramble antisense-treated and control cells were subjected to ChIP with MLL4, H3K4 tri-methyl, RNAPII and $\beta$-actin (control) antibodies. The immunoprecipitated DNA fragments were PCR amplified by using primers specific to the $\beta$-actin (ORF, as control) and promoters of cyclin B, cyclin D, p27, HOXA5 and HOXB7 genes. The real-time quantification is on the bottom panel. Bars indicate standard errors $(n=3)$. 
such as cyclins, p-proteins and selected HOX genes. Notably, the dynamic expression and degradation of cyclins and p-proteins are associated with progression of cell cycle through different phases. The cyclins (such as cyclin A-E) bind to cell cycle-specific cyclindependent kinases (cdks) and facilitate progression of cell cycle. Similarly, the p-proteins (such as p21, p27 and p53) have both positive and negative roles in cell-cycle progression (Ansari and Mandal, 2010). For example, p27 that acts as cdk inhibitor exerts both positive and negative regulation of cdk4 activity at G1/S-phase transition (Poon et al, 1995). HOX genes also have crucial roles in cell-cycle progression. For example, HOXA5 binds to anti-apoptotic protein, Twist and restore the inhibitory effects of Twist on p53-target genes during cell cycle (Stasinopoulos et al, 2005). HOXB7 knockdown results in cell-cycle arrest at G1 phase via downregulation of cyclin D1 and cyclin E (Liao et al, 2011). Our results demonstrated that MLL4 knockdown downregulated the expression of cyclin D, cyclin E, p27, HOXA5 and HOXB7 genes (Figure $3 \mathrm{~A}$, real-time quantifications are in right panel). Temporal studies demonstrated that level of expression of MLL4-target genes (such as cyclin D and HOXA5) was correlated with the level of MLL4 knockdown at different times (24, 48 and $72 \mathrm{~h}$ ) after MLL4 antisense treatment (Supplementary Figure S4).

ChIP assay demonstrated that MLL4 was bound to the promoters of cyclin $B$, cyclin $D, p 27, H O X A 5$ and HOXB7 genes and these bindings were decreased upon knockdown of MLL4 (Figure 3B, real-time quantification in the bottom panels). Similarly, level of RNAPII and H3K4 trimethylation (a critical mark of gene activation) were also decreased upon MLL4 knockdown (Figure 3B). The $\beta$-actin was not bound to the target gene promoters irrespective of MLL4 knockdown. Scramble antisense has no significant impact on the binding of MLL4, RNAPII and level of H3K4 trimethylation in the target gene promoters. These results demonstrated that MLL4 regulates cellcycle regulatory genes via binding to the promoters and increasing H3K4 trimethylation and facilitating RNAPII recruitment.

\section{Depletion of MLL4 suppressed tumour growth in vivo in colon cancer xenograft}

As MLL4 antisense induced efficient and preferential apoptosis in colon cancer cells, we examined its efficacy in downregulating tumour growth in vivo using a human colon cancer xenograft. Initially, we examined toxicity of the MLL4 and scramble antisenses on nude mice. We injected intraperitoneally three different doses (100-500 $\mu$ g per $20 \mathrm{~g}$ body weight) of MLL4 and scramble antisense into 6-week-old mouse (three replicates), monitored their health and behaviour for a month and we found that all mice survived grew similarly to control mice without loss
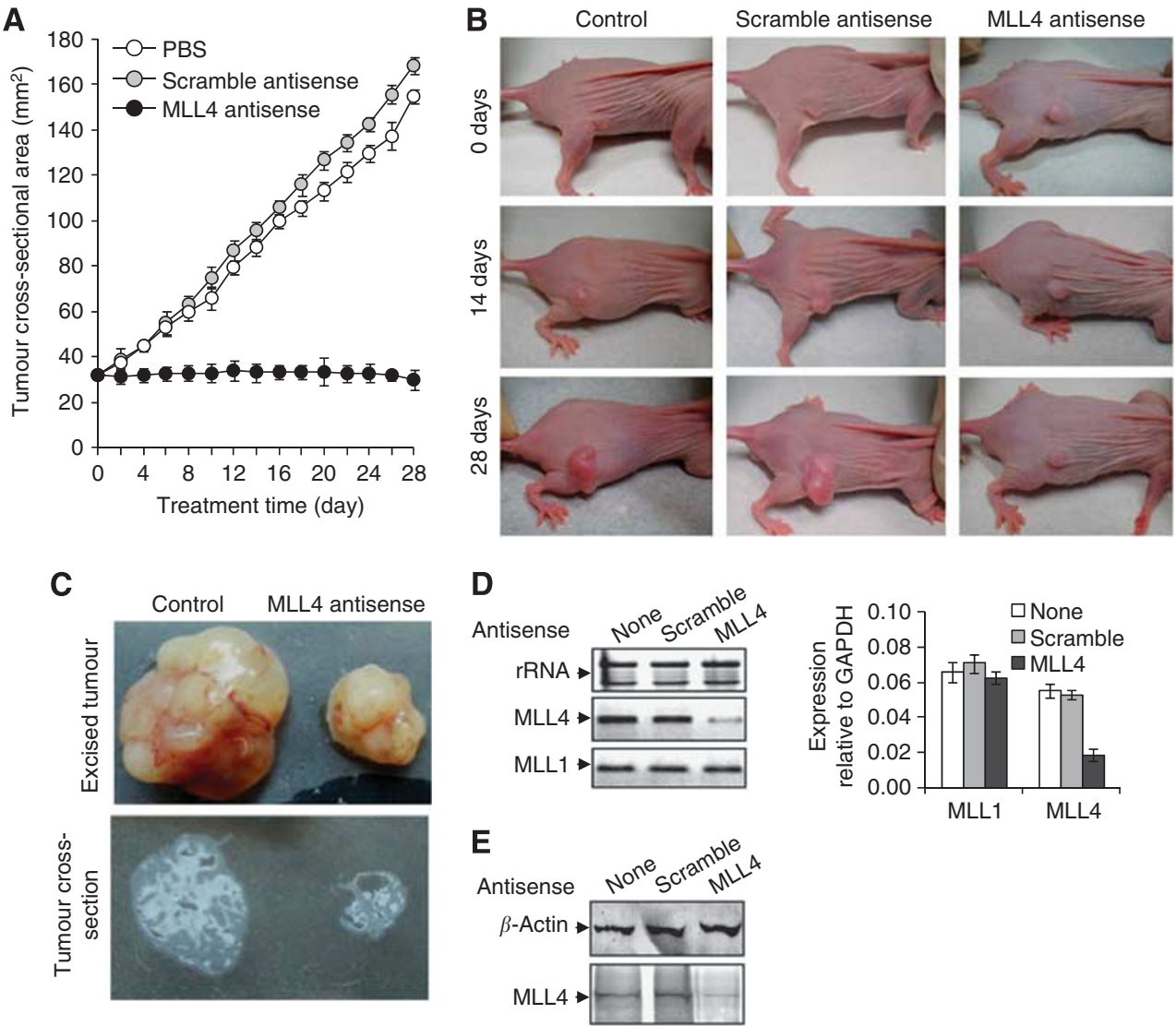

Figure 4 Regression of colon cancer xenograft by MLL4 antisense. SW480 cells were subcutaneously injected on the right hinge region of 6-week-old athymic nude (nu/nu) mice. Once the tumour reached about $32 \mathrm{~mm}^{2}$ of cross-sectional area, mice were intraperitoneally administered with MLL4 antisense (300 $\mu \mathrm{g}$ per $20 \mathrm{~g}$ body weight) on the left hinge region at 4 days interval for 4 weeks. Control mice were administered with either PBS (diluents) or a same doze of scramble antisense (with no homology with MLL4). Tumour sizes were measured using a slid caliper at every 2 days intervals. (A) Cross-sectional area of the tumours was plotted against time. Bars indicated standard errors. (B) Representative pictures of the control and antisense-treated mice at different stages. (C) Tumour xenografts excised at 28th day of treatment. The cross-section of tumours showing internal issue is in bottom panel. (D) The RNA extract of the excised tumour was analysed by RT-PCR with primer specific to MLL4 and MLLI (specificity control). rRNA was used as quantitative control. The real-time quantification is on the right panel. Bars indicate standard errors $(n=3)$. (E) The western blot of the protein extract of the excised tumour was done with MLL4 and $\beta$-actin (control) antibody. 
A
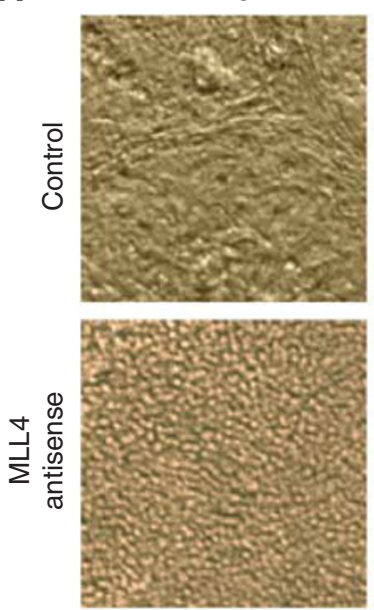

DAPI
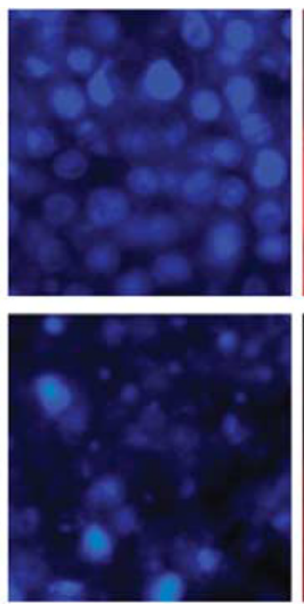

MLL4
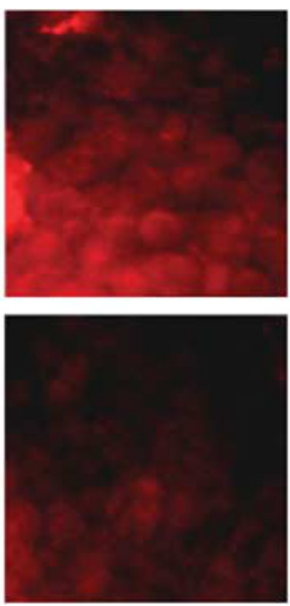

Merge
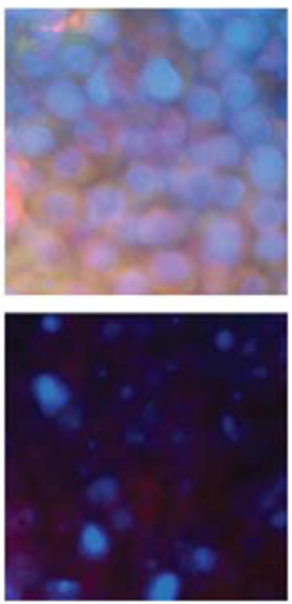

B
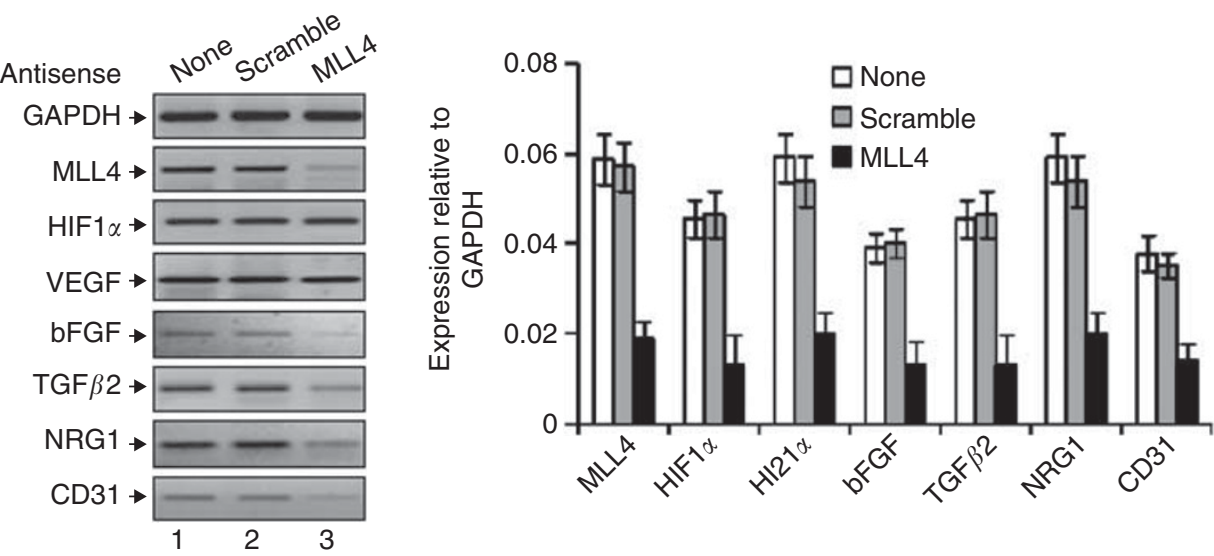

C
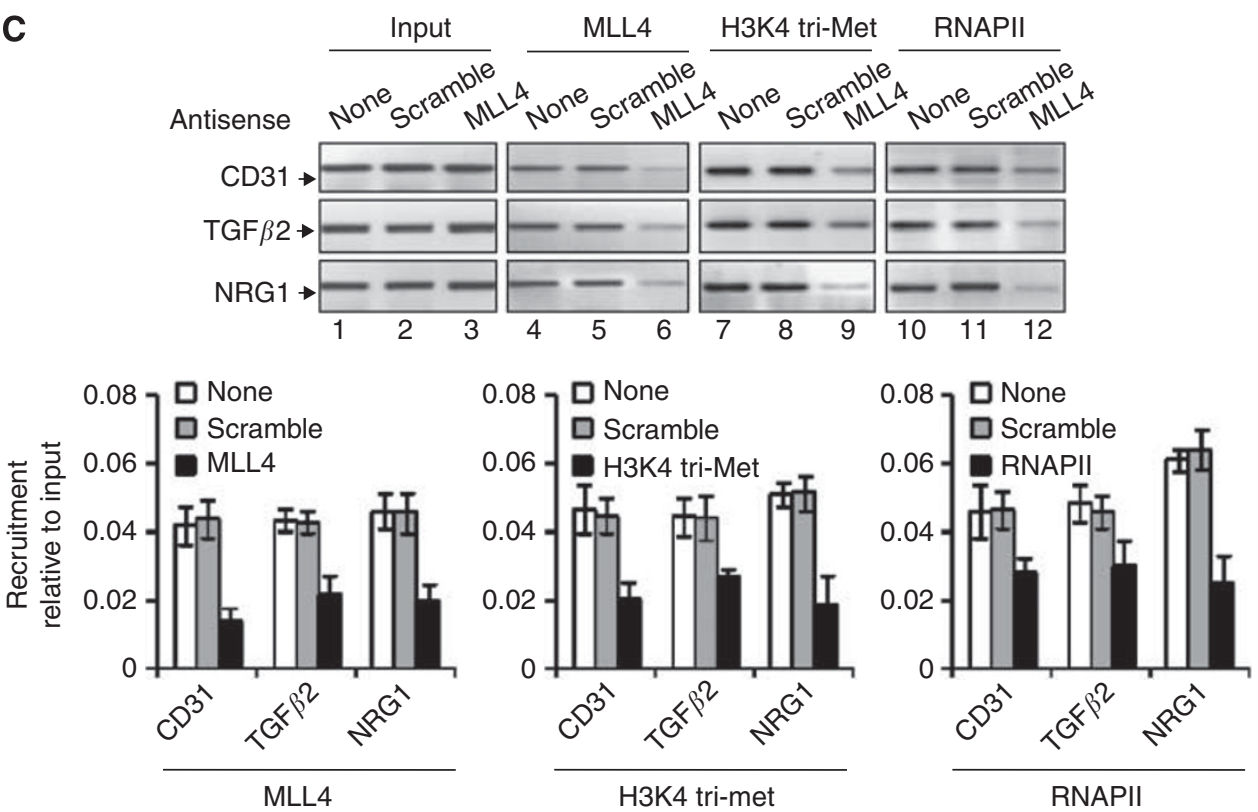

Figure 5 MLL4 knockdown affects nuclear integrity and expression of growth and angiogenic factors in xenografted tumour. The MLL4 antisense-treated or control mice with colon cancer xenograft were either euthanised to excise the tumour xenograft or perfused with $4 \%$ paraformaldehyde at 28 th day of treatment. (A) Immunolocalisation of MLL4 and nuclear integrity: Formaldehyde-fixed tumours were sectioned, immunostained with MLL4 antibody and DAPI (for nuclear staining) and analysed under fluorescence microscope. Representative images showing the cellular morphology (DIC), nuclear integrity (DAPI) and MLL4 expression in the control and MLL4 antisense-treated tumours are shown. (B) MLL4 regulates expression of growth and angiogenic factors in vivo: RT-PCR analysis of the RNA extracted from MLL4 antisense-treated tumour tissues by using primers specific to MLL4, VEGF, bFGF, TGF $\beta 2$, CD3I, HIFI $\alpha$ and $\beta$-actin (control). The real-time quantification (relative to GAPDH) is shown in right panel. Bars indicate standard error. (C) The tumour tissue was analysed by ChIP assay using MLL4, H3K4-trimethyl and RNAP II antibodies. The ChIP DNA was analysed by PCR with primers specific to the promoter regions of CD3I, TGF $\beta 2$ and NRGI. qPCR data are the right panel. 
of body weight indicating no significant animal toxicity of MLL4 antisense.

To examine the impact of MLL4 knockdown in tumour growth, we applied MLL4 antisense on colon cancer xenograft implanted on nude mouse. Colon cancer xenograft was developed in nude mice by injecting SW480 cells near the right back limb (Singhal et al, 2007). Once the tumour size reached $\sim 30 \mathrm{~mm}^{2}$, we administered MLL4 antisense intraperitoneally $(300 \mu \mathrm{g}$ per $20 \mathrm{~g}$ body weight, in three parallel replicates) on a different spatial location (left back limb) away from the xenografted tumour. Control mice were injected with equal volume of diluents (PBS) or scramble antisense alone. Growth of tumour (tumour size) was monitored over time and plotted (Figure 4A). As seen in Figure 4A, the sizes of the control or scramble antisense-treated tumours were increased exponentially over time. Interestingly, application of MLL4 antisense suppressed the growth of colon cancer xenograft completely with slight regression of original tumour (before application of antisense; Figure 4A). Representative pictures of mice bearing tumours are shown in Figure 4B. These results demonstrated that MLL4 is critical for colon tumour growth in vivo.

To examine the tumour histology and target validation, we excised out the control as well as MLL4 antisense-treated tumours from the mice and subjected to mRNA and protein analysis, and tissue immunohistochemistry analysis. The control tumours are bigger in size and were tightly attached to the host mice tissue while the MLL4 antisense-treated tumours were very small (Figure 4C, tumour dissections are shown in the bottom panel). The RNA and proteins from homogenised tumour tissue were subjected to $\mathrm{GPCR}$ and western blotting. Our results demonstrated that application of MLL4 antisense specifically knocked down MLL4 in both mRNA (but not MLL1, qPCR data on the right panel) and protein levels (Figure 4D and E). Scramble antisense has no significant impact on MLL4 gene expression. These results demonstrated that MLL4 antisense has reached the xenografted tumour tissue systemically and specifically knocked down MLL4. Although mechanism of delivery of MLL4 antisense to the xenografted tumour tissue is not clear at this point, systemic administration of antisense oligonucleotides and siRNAs (via intraperitoneal injection) for downregulating various other target genes and suppressing of tumour growth in xenograft models has been reported earlier (Wang et al, 2002; Tammali et al, 2006; Singhal et al, 2007).

To investigate the effect of MLL4 knockdown on tumour tissue, we immunostained tumour sections with MLL4 antibody and DAPI and analysed under a fluorescence microscope. In the control tumour, cell nuclei were normal, round to oval shaped, and stained uniformly with DAPI, indicating healthy states of cells (Figure 5A). In the MLL4-knocked down xenograft, the cell nuclei were fragmented and condensed indicating dead cells. Immunostaining showed higher level of MLL4 localisation primarily in the cell nuclei of the control xenograft tissues, while in the MLL4 antisense-treated xenograft, MLL4 was localised in patches of fragmented nuclei and the level of expression of the protein was relatively less compared with the untreated control. These condensation and disintegration of cell nuclei upon MLL4 knockdown indicated that MLL4 is critical for tumour cell survival and growth in vivo and therefore, knockdown of MLL4 induced cell death inside the xenografted tumour leading to disintegration of core tumour tissue and tumour suppression.

As MLL4 knockdown induced suppression of tumour growth, we examined if MLL4 knockdown also affected the expression of tumour growth and angiogenic factors such as TGF $\beta 1$, bFGF, NRG1, HIF1 $\alpha$, VEGF and CD31 using qPCR (Roskoski, 2007; Wendt et al, 2010; Favaro et al, 2011). These analyses demonstrated that MLL4 knockdown suppressed the expression of CD31, bFGF, TGF $\beta 2$, NRG1 along with MLL4 (Figure 5B). ChIP (with tumour tissue) analysis showed that knockdown of MLL4 resulted in decreased level of histone $\mathrm{H} 3 \mathrm{~K} 4$ trimethylation and RNAPII recruitment (as well as MLL4 recruitment) at the promoters of CD31, TGF $\beta 2$, NRG1 but not bFGF genes (Figure 5C). The decrease in $\mathrm{H} 3 \mathrm{~K} 4$ trimethylation at the promoters of CD31, TGF $32, N R G 1$ genes, upon MLL4 depletion, suggested that MLL4-mediated histone methylation is crucial for expression of tumour growth factors. These results demonstrated that MLL4 is a key regulator of tumour growth factors and hence tumour growth.

In summary, our results demonstrated that MLL4 is a key player in cell-cycle regulation. Knockdown of MLL4 resulted in cell-cycle defect and induced apoptosis in colon cancer cells. The MLL4 regulates the expression of various cyclins, p-proteins and HOX genes that are critical players in cell-cycle progression, via histone H3K4 trimethylation and RNAPII recruitment in the target gene promoters. Importantly, systemic application of MLL4 antisense in nude mice bearing colon cancer xenograft resulted in specific knockdown of MLL4 in xenografted colon tissue, inducing cell death and suppression of tumour growth almost to the basal level. Knockdown of MLL4 suppressed expression of various tumour growth and angiogenic factors such as CD31, bFGF, TGF $\beta 2$ and NRG1 in the tumour tissue via downregulation of promoter H3K4 trimethylation and RNAPII recruitment and thus resulting in suppression of the growth of xenografted tumour. Notably, there are four different MLL family of histone H3K4-specific HMTs, MLL1, MLL2, MLL3 and MLL4 in human. Both MLL3 and MLL4 are part of the ASCOM complex and have an important role in NRmediated gene activation (Lee et al, 2008b; Ansari and Mandal, 2010). The MLL3 and MLL4 functionally interacts with oestrogen receptors, RXRs and liver-x-receptors during respective liganddependent gene activation (Lee et al, 2008b; Ansari and Mandal, 2010). The MLL3 and MLL4 also participate in PPAR-mediated adipogenesis (Lee et al, 2008a). In addition, MLL2 has also been shown to interact with NRs, regulate hormone-induced gene expression and has an important role in oocytes (Dreijerink et al, 2006; Mo et al, 2006). Because of similar catalytic SET domains present in all four MLL proteins (MLL1-4), it may be possible that they have redundant functions. In fact, recent studies demonstrated that MLL2 and MLL3 bindings were exchanged with MLL1 and MLL4 at the HOXC6 promoter during oestrogen-induced HOXC6 expression, indicating distinct roles of different MLLs during basal and activated gene transcription, beyond their histone methylation activity (Ansari et al, 2011). However, in the present study, we did not observe any replacement of MLLs (MLL1-3) in the MLL4-target gene promoters (cyclin D, cyclin E, p27, HOXA5, HOXB7, CD31, bFGF, TGF $\beta 2$ and NRG1) under MLL4-knockdown environment (data not shown). However, histone H3K4 trimethylation level along with RNAPII was decreased upon knockdown of MLL4 (Figure 3B and 5C). These observations indicated that MLL4 is a crucial regulator of promoter histone $\mathrm{H} 3 \mathrm{~K} 4$ trimethylation and transcription of target genes and this may not be compensated by the presence of other MLLs in the cell at least in set of target genes examined. Overall, our studies demonstrated that MLL4 is critical for survival and growth of tumour cells both in vitro and in vivo and therefore open up new avenues for potential cancer therapy.

\section{ACKNOWLEDGEMENTS}

We thank Mandal laboratory members for discussion. We thank Dr Linda Perrotti and Samara Morris-Bobzean for their help with tissue sectioning. Mandal research is supported by grants from NIH (1R15 ES019129-01, 2R15 CA113747-02).

Supplementary Information accompanies the paper on British Journal of Cancer website (http://www.nature.com/bjc) 


\section{REFERENCES}

Ajiro K, Allis CD (2002) Histone code hypothesis. Tanpakushitsu Kakusan Koso 47: 753-760

Ansari KI, Grant JD, Woldemariam GA, Kasiri S, Mandal SS (2009) Iron(III)-salen complexes with less DNA cleavage activity exhibit more efficient apoptosis in MCF7 cells. Org Biomol Chem 7: 926-932

Ansari KI, Hussain I, Kasiri S, Mandal SS (2012) HOXC10 is overexpressed in breast cancer and transcriptionally regulated by estrogen via involvement of histone methylases MLL3 and MLL4. J Mol Endocrinol 48: $61-75$

Ansari KI, Hussain I, Shrestha B, Kasiri S, Mandal SS (2011) HOXC6 Is transcriptionally regulated via coordination of MLL histone methylase and estrogen receptor in an estrogen environment. J Mol Biol 411: 334-349

Ansari KI, Mandal SS (2010) Mixed lineage leukemia: roles in gene expression, hormone signaling and mRNA processing. FEBS $J$ 277: 1790-1804

Bannister AJ, Kouzarides T (2005) Reversing histone methylation. Nature 436: $1103-1106$

Bhaumik SR, Smith E, Shilatifard A (2007) Covalent modifications of histones during development and disease pathogenesis. Nat Struct Mol Biol 14: 1008-1016

Dou Y, Milne TA, Ruthenburg AJ, Lee S, Lee JW, Verdine GL, Allis CD, Roeder RG (2006) Regulation of MLL1 H3K4 methyltransferase activity by its core components. Nat Struct Mol Biol 13: 713-719

Dreijerink KM, Mulder KW, Winkler GS, Hoppener JW, Lips CJ, Timmers HT (2006) Menin links estrogen receptor activation to histone H3K4 trimethylation. Cancer Res 66: 4929-4935

Favaro E, Lord S, Harris AL, Buffa FM (2011) Gene expression and hypoxia in breast cancer. Genome Med 3: 55

Guenther MG, Jenner RG, Chevalier B, Nakamura T, Croce CM, Canaani E, Young RA (2005) Global and Hox-specific roles for the MLL methyltransferase. Proc Natl Acad Sci USA 102: 8603-8608

Hess JL (2004) MLL: a histone methyltransferase disrupted in leukemia Trends Mol Med 10: 500-507

Hoeksema KA, Jayanthan A, Cooper T, Gore L, Trippett T, Boklan J, Arceci RJ, Narendran A (2011) Systematic in-vitro evaluation of the NCI/NIH Developmental Therapeutics Program Approved Oncology Drug Set for the identification of a candidate drug repertoire for MLL-rearranged leukemia. Onco Targets Ther 4: 149-168

Kouzarides T (2007) Chromatin modifications and their function. Cell 128 693-705

Lee J, Kim DH, Lee S, Yang QH, Lee DK, Lee SK, Roeder RG, Lee JW (2009) A tumor suppressive coactivator complex of p53 containing ASC-2 and histone H3-lysine-4 methyltransferase MLL3 or its paralogue MLL4. Proc Natl Acad Sci USA 106: 8513-8518

Lee J, Saha PK, Yang QH, Lee S, Park JY, Suh Y, Lee SK, Chan L, Roeder RG, Lee JW (2008a) Targeted inactivation of MLL3 histone H3-Lys-4 methyltransferase activity in the mouse reveals vital roles for MLL3 in adipogenesis. Proc Natl Acad Sci USA 105: 19229-19234

Lee S, Lee J, Lee SK, Lee JW (2008b) Activating signal cointegrator-2 is an essential adaptor to recruit histone $\mathrm{H} 3$ lysine 4 methyltransferases MLL3 and MLL4 to the liver X receptors. Mol Endocrinol 22: 1312-1319

Liao WT, Jiang D, Yuan J, Cui YM, Shi XW, Chen CM, Bian XW, Deng YJ, Ding YQ (2011) HOXB7 as a prognostic factor and mediator of colorectal cancer progression. Clin Cancer Res 17: 3569-3578

Marschalek R (2010) Mixed lineage leukemia: roles in human malignancies and potential therapy. FEBS $J$ 277: 1822-1831
Mishra BP, Ansari KI, Mandal SS (2009) Dynamic association of MLL1, H3K4 trimethylation with chromatin and Hox gene expression during the cell cycle. FEBS J 276: 1629-1640

Mo R, Rao SM, Zhu YJ (2006) Identification of the MLL2 complex as a coactivator for estrogen receptor alpha. J Biol Chem 281: 15714-15720

Orrenius S, Gogvadze V, Zhivotovsky B (2007) Mitochondrial oxidative stress: implications for cell death. Annu Rev Pharmacol Toxicol 47: 143-183

Parsons DW, Li M, Zhang X, Jones S, Leary RJ, Lin JC, Boca SM, Carter H, Samayoa J, Bettegowda C, Gallia GL, Jallo GI, Binder ZA, Nikolsky Y, Hartigan J, Smith DR, Gerhard DS, Fults DW, VandenBerg S, Berger MS, Marie SK, Shinjo SM, Clara C, Phillips PC, Minturn JE, Biegel JA, Judkins AR, Resnick AC, Storm PB, Curran T, He Y, Rasheed BA, Friedman HS Keir ST, McLendon R, Northcott PA, Taylor MD, Burger PC, Riggins GJ, Karchin R, Parmigiani G, Bigner DD, Yan H, Papadopoulos N, Vogelstein B, Kinzler KW, Velculescu VE (2011) The genetic landscape of the childhood cancer medulloblastoma. Science 331: 435-439

Pasqualucci L, Trifonov V, Fabbri G, Ma J, Rossi D, Chiarenza A, Wells VA, Grunn A, Messina M, Elliot O, Chan J, Bhagat G, Chadburn A, Gaidano G, Mullighan CG, Rabadan R, Dalla-Favera R (2011) Analysis of the coding genome of diffuse large B-cell lymphoma. Nat Genet 43: 830-837

Paulussen AD, Stegmann AP, Blok MJ, Tserpelis D, Posma-Velter C, Detisch Y, Smeets EE, Wagemans A, Schrander JJ, van den Boogaard MJ van der Smagt J, van Haeringen A, Stolte-Dijkstra I, Kerstjens-Frederikse WS, Mancini GM, Wessels MW, Hennekam RC, Vreeburg M, Geraedts J, de Ravel T, Fryns JP, Smeets HJ, Devriendt K, Schrander-Stumpel CT (2010) MLL2 mutation spectrum in 45 patients with Kabuki syndrome. Hum Mutat 32: E2018-E2025

Poon RY, Toyoshima H, Hunter T (1995) Redistribution of the CDK inhibitor p27 between different cyclin.CDK complexes in the mouse fibroblast cell cycle and in cells arrested with lovastatin or ultraviolet irradiation. Mol Biol Cell 6: 1197-1213

Roskoski Jr R (2007) Vascular endothelial growth factor (VEGF) signaling in tumor progression. Crit Rev Oncol Hematol 62: 179-213

Singhal SS, Singhal J, Yadav S, Dwivedi S, Boor PJ, Awasthi YC, Awasthi S (2007) Regression of lung and colon cancer xenografts by depleting or inhibiting RLIP76 (Ral-binding protein 1). Cancer Res 67: 4382-4389

Stasinopoulos IA, Mironchik Y, Raman A, Wildes F, Winnard Jr P, Raman V (2005) HOXA5-twist interaction alters p53 homeostasis in breas cancer cells. J Biol Chem 280: 2294-2299

Tammali R, Ramana KV, Singhal SS, Awasthi S, Srivastava SK (2006) Aldose reductase regulates growth factor-induced cyclooxygenase-2 expression and prostaglandin E2 production in human colon cancer cells. Cancer Res 66: 9705-9713

Tan YC, Chow VT (2001) Novel human HALR (MLL3) gene encodes a protein homologous to ALR and to ALL-1 involved in leukemia, and maps to chromosome 7q36 associated with leukemia and developmental defects. Cancer Detect Prev 25: 454-469

Wang H, Hang J, Shi Z, Li M, Yu D, Kandimalla ER, Agrawal S, Zhang R (2002) Antisense oligonucleotide targeted to RIalpha subunit of cAMP-dependent protein kinase (GEM231) enhances therapeutic effectiveness of cancer chemotherapeutic agent irinotecan in nude mice bearing human cancer xenografts: in vivo synergistic activity, pharmacokinetics and host toxicity. Int J Oncol 21: 73-80

Wendt MK, Smith JA, Schiemann WP (2010) Transforming growth factorbeta-induced epithelial-mesenchymal transition facilitates epidermal growth factor-dependent breast cancer progression. Oncogene 29: 6485-6498

This work is published under the standard license to publish agreement. After 12 months the work will become freely available and the license terms will switch to a Creative Commons Attribution-NonCommercial-Share Alike 3.0 Unported License. 